push the panel all the way into the sharp corners of the original mold.

In tests, the researchers were able to form aluminum door panels that closely matched the shape of their steel counterparts without tears or wrinkles. They also performed formability tests on both agehardened and non-hardenable aluminum-two types of the metal used commercially-and found both exhibited tremendous gains with this process.

While traditional stamping can stretch most aluminum alloys to a maximum of $30 \%$ of their original length before tearing, Daehn and colleagues have stretched parts a full $100 \%$ without tearing. Also, tests have shown this process does not degrade the material.

"That extra elongation enables us to form many complicated parts that are otherwise difficult to impossible," Daehn said.

These tests were performed with two steps, first the stamping and then the electromagnetic forming. But Daehn envisions that manufacturers could install electromagnet coils within a die and perform both steps at the same time. According to this scenario, when the mold closes, the aluminum will first conform to the softer shape of the tool. Then, the electromagnetic force from the coils will push the metal the rest of the way into the die. As Daehn describes it, the part would "pop into shape."

Daehn said manufacturers already use electromagnetics for assembly, but not for sheet-metal forming.

\section{Hydrogen Peroxide could Power Future Fuel Cell}

Researchers at Purdue University are developing a hydrogen peroxide-based material into a type of environmentally friendly fuel cell that runs on aluminum and renewable resources and generates about 20 times more electricity per pound than car batteries. Stephen Heister, a professor of aeronautics and astronautics at Purdue, said that the mixture consists of $3 \%$ water and $97 \%$ hydrogen peroxide and has had its critical contaminants removed.

As described in a poster presented at the Second International Hydrogen Peroxide Propulsion Conference at Purdue, this purified, concentrated form of $\mathrm{H}_{2} \mathrm{O}_{2}$ is broken down with chemical catalysts, yielding oxygen that combusts with alcoholbased fuels such as methanol or ethanol, which can be derived from corn. The researchers said that in the fuel cells, hydrogen peroxide serves two roles: It is a "catholyte," meaning it is both the electrolyte and the cathode. The aluminum serves as the cell's fuel and its anode; as it oxidizes, it gives up electrons. Waste products include water and recyclable chemical compounds.

In the past, attempts to develop the cells were abandoned because the reaction with aluminum quickly formed a thick sludge that hindered the flow of electricity. However, because Heister and his colleagues did not have pure aluminum for their work, they used an aluminum alloy and found that the alloy did not form the sludge.

Engineering student Kok Hong Lim said that one problem with the experimental cells is that, unlike batteries, they do not immediately provide a steady supply of electricity; the cells take about $2 \mathrm{~h}$ to reach their peak electrical output before producing a steady current flow.

John Rusek, an assistant professor of aeronautics and astronautics at Purdue, said that aluminum was chosen originally because it is an abundant natural resource and is readily available from recycled sources. He estimates that the cells are at least 20 times higher in energy density than a standard lead-acid car battery. He said that other metals, such as lithium alloys, might also work in hydrogenperoxide fuel cells.

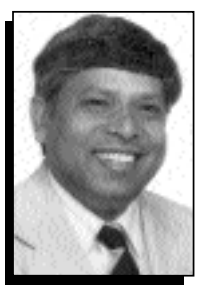

\section{ASM Gold Medal} Awarded to Narayan

Jagdish Narayan, Distinguished University Professor of Materials Science and Engineering at North Carolina State University, is the recipient of the 1999 ASM Gold Medal, the highest honor given by ASM-International, for his seminal contributions in the area of laser processing, defects and interfaces, structure-property correlations, and modeling of novel and advanced materials. He was honored on November 2 during the ASM-International's annual meeting in Cincinnati.

Narayan joined the University in 1984, where he directs the NSF Center for Advanced Materials and Smart Structures, after working as a senior scientist and group leader for 12 years at Oak Ridge National Laboratory. He received his master's (1970) and PhD degree (1971) from the University of California-Berkeley, and his bachelor's degree with highest honors and distinction from the Indian Institute of Technology, India, in materials science and engineering. He has published over 700 papers, edited eight books, and holds 15 patents. Narayan served on the Materials Research Society council (1984-1987) and co-chaired the 1984 MRS Fall Meeting. He is a member of MRS and a Fellow of the American Physical Society; the American Association for the Advancement of Science; the Minerals, Metals \& Materials Society; and ASM-International.

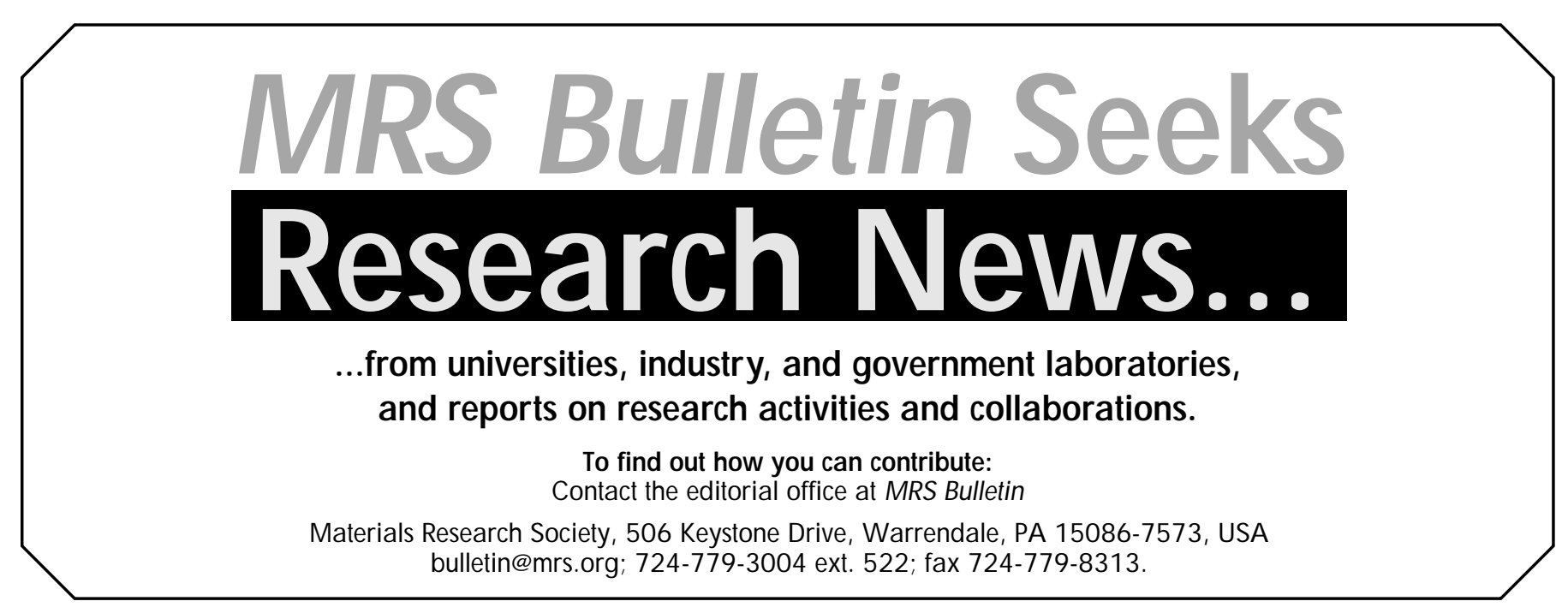

